\title{
ÁFRICA EN FEMENINO: UNA APROXIMACIÓN A SU(S) LITERATURA(S)
}

\author{
Alba Rodríguez-García \\ Université Gaston Berger, Senegal \\ alba-rodriguez.garcia@ugb.edu.sn
}

\section{Resumen}

La «literatura poscolonial» eurófona constituye una de las corrientes literarias africanas mejor definidas y delimitadas, y una de las más estudiadas en las últimas décadas por su especial creatividad e idiosincrasia. La explosión de publicaciones en lenguas eurófonas ocurrió a mediados del siglo xx y desde aquel entonces no ha parado de evolucionar. En este contexto, si bien las escritoras africanas no han recibido tanta atención como sus congéneres masculinos, su producción literaria ha estado al mismo nivel y ha sido tan dinámica y rompedora como la de ellos. Esta contribución tiene como objetivo trazar una descripción general de la literatura africana, para centrarse a continuación en la escritura femenina colonial y poscolonial, con el fin de ofrecer un acercamiento a las actuales producciones continentales y diaspóricas de estas escritoras contemporáneas que sirva para celebrar las contribuciónes y las producciones de las diferentes generaciones de creadoras en la escena literaria mundial.

PALABRAS ClaVE: mujeres, literatura africana, diáspora, colonialismo, poscolonialismo.

\author{
AFRICA IN WOMEN: AN APPROACH \\ TO THEIR LITERATURE(S)
}

\section{Abstract}

Postcolonial African Europhone Literature constitutes probably not only one of the best defined and delimited African literary currents but one of the most studied in recent decades for its special creativity and idiosyncrasy. The explosion of publications in europhone languages happened in the middle of the xx century and since then it has not stopped evolving. While African women writers have not received as much attention as their male counterparts, their literary activity has been at the same level and has been as dynamic and disruptive as theirs. In this sense, this article intends to draw a general description of African literature that will enable us to frame what regards to both colonial and postcolonial feminine writing in order to finally offer an approach to the current continental and diasporic productions by female writers. The aim being celebrating the contribution and productions to the worldwide literary scene of their different generations.

KeYwords: women, African literature, diaspora, colonialism, postcolonialism.

DOI: http://doi.org/10.25145/j.atlantid.2018.09.005

Revista Atlántida, 9; diciembre 2018, pp. 91-105; ISSN: e-2530-853X 


\section{INTRODUCCIÓN A LA(S) LITERATURA(S) AFRICANA(S)}

But there was something which we tried to do and failed -that was to define 'African Literature' satisfactorily.

Chinua Achebe (1965)

La historia de la literatura en África es vasta, heterogénea y compleja; sus inicios y elementos principales se resisten a ser bien definidos nítidamente, y su continua evolución no ha parado de darle nueva(s) forma(s). Quienes se dedican a su estudio coinciden en ciertas afirmaciones, que intentaré sintetizar en las siguientes líneas siguiendo un hilo conductor: el de las recientes publicaciones que se han preocupado y ocupado de ella. Empezaré haciendo una necesariamente sucinta exposición general de la historia de la literatura en África, para poder adentrarnos en materia y abordar los aspectos que se nos antojan indispensables, con el fin de presentar un acercamiento al nacimiento y a la evolución de la literatura africana femenina.

Teniendo en cuenta que África es el segundo continente más grande del mundo y el segundo más poblado, no debe hacérsenos difícil imaginar la diversidad sociopolítica y económica, lingüística, étnica, cultural y, por ende, literaria que esta vasta tierra presenta. Como indica Cooper (2009/2002: 11), «at any moment, Africa appears as a mixture of diverse languages and diverse cultures; indeed, linguistically alone, it is the most varied continent on earth». Es innegable, por obvio, la existencia de producción literaria (fundamentalmente oral) en África desde el principio de los tiempos y, si bien no hay datos exactos o pruebas fiables de las manifestaciones primeras y más ancestrales, se sabe que su tradición es tan antigua como el propio continente, como bien asegura Eileen Julien en su brillante artículo titulado Literature in Africa (2014: 209):

We have no records of the earliest oral traditions, but we know verbal arts in Africa, oral and written, are ancient and long preceded the modern era, characterized by European colonialism and the introduction of European languages. African literature can be said to include Egyptian texts from the second and third millennia BCE; the sixth-century Latin-language texts of Agustine Hippo; texts produced in Ge'ez, the ancient language of the region that has become Ethiopia, such as those of the Axumite period (four to seven centuries); and Arabic language texts, such as those of fourteenth-century North Africa, seventeenth century Timbuktu in western Sahel, and the nineteenth-century eastern coast of Africa. And alongside the widely known contemporary traditions in imported but now Africanized languages and forms, there is ongoing written and oral production in indigenous languages such as Amharic, Kishwahili, Pulaar, Yoruba and Zulu.

Así, la idea general que se tiene de que la literatura nace en África tras la llegada de las civilizaciones árabes o europeas es considerada hoy en día absolutamente errada, y la creencia occidental de que el «fundador y primer representante» de la literatura africana fue el nigeriano Chinua Achebe con Things Fall Apart (1958) ya 
es también historia ${ }^{1}$. No solo la literatura oral en forma de cuento, poema, mito, épica, rezo o proverbio estaba ya presente antes de la época que se señala, sino que las producciones literarias africanas siguen empapadas de ella, constituyendo esto precisamente uno de sus rasgos más destacados. Igualmente, la literatura escrita se hizo presente tempranamente, como lo demuestran los jeroglíficos de la época del gran imperio egipcio (por citar un solo ejemplo), que, al parecer, circularon por varias zonas del continente. Junto a ello, un ciertamente abundante conjunto de posteriores manifestaciones literarias en lenguas y dialectos locales, a veces minoritarios, algunos en escritura aljamiada ${ }^{2}$ y, por supuesto, en árabe y más tarde, a partir de los siglos sucesivos, en diversas lenguas europeas (inglés, francés o portugués), trazaron la historia de la producción literaria del continente africano.

Teniendo en cuenta el volumen y la diversidad de las producciones literarias africanas, uno de los primeros problemas a los que nos enfrentamos al abordar estas escrituras es el de su clasificación, tarea altamente complicada debido a la multiplicidad de criterios que pueden utilizarse, y de hecho se han utilizado, para ello. Ya en 1962 se preguntaba el propio Chinua Achebe, con motivo de la Conferencia de Escritores Africanos ${ }^{3}$ celebrada en la Universidad de Makerere (Kampala, Uganda), lo siguiente:

... Was it literature produced in Africa or about Africa? Could African literature be on any subject, or must it have an African theme? Should it embrace the whole

${ }^{1}$ En un artículo publicado por Nick Clark en 2013 en el diario británico Independent, leemos: «In 2007, he won the Man Booker International Prize, where judge Nadine Gordimer dubbed him the "father of modern African literature"». Disponible en http://www.independent.co.uk/ arts-entertainment/books/news/father-of-modern-african-literature-achebe-82-dies-after-short-illness-8545670.html. Pero ya leíamos en un artículo publicado en The Guardian de 2009 por Alison Flood, titulado Achebe rejects endorsement as 'father of modern African literature', que el propio Achebe «resisted that very, very strongly», y cita las palabras del autor a este respecto: "It's really a serious belief of mine that it's risky for anyone to lay claim to something as huge and important as African literature [...] the contribution made down the ages. I don't want to be singled out as the one behind it because there were many of us -many, many of us». Disponible en http://www.theguardian.com/ books/2009/nov/12/achebe-rejects-father-modern-african-literature.

2 Respecto de estas literaturas, véanse los trabajos de Fallou Ngom, profesor de la Boston University, especialista en la materia, como, por ejemplo: «Ajami scripts in the Senegalese speech community», publicado en 2010.

${ }^{3}$ En la web creada por la Universidad de Makerere con motivo de la celebración de su noventa aniversario en el año 2012, definieron este evento como sigue: «Soon after Uganda gained independence from Great Britain in 1962, Makerere University hosted its first significant international gathering, the first African Writers Conference. The conference was a milestone in African literature dealing directly with the legacy of colonialism. It attracted a number of African writers such as Chinua Achebe and Wole Soyinka who would eventually become internationally famous. Other prominent African writers who attended include Ezekiel Mphahlele, Lewis Nkosi, Ngũgĩ wa Thiong'o (then known as James Ngugi) and Rajat Neogy (founder of Transition Magazine). The Conference also helped spread the institution's reputation beyond East Africa. By the mid-1960s Makerere University was the largest and most distinguished university in Sub-Saharan Africa». Disponible en <http://90.mak.ac.ug/timeline/first-makerere-african-writers-conference-1962>. 
continent or South of the Sahara, or just Black Africa? And then the question of language. Should it be in indigenous African languages or should it include Arabic, English, French, Portuguese, Afrikaans, etc.?

Así, dependiendo del tipo de criterio que utilicemos, estas literaturas pertenecerán a unas u otras esferas, a unos u otros tipos, a unas y otras clases de escrituras, pues «there are many ways to divide the terrain of literature written by Africans» (Julien, 2014: 212).

Por regiones, se hablaría, por ejemplo, de literatura del África occidental frente a la del África del este; por etnias, podríamos separar la literatura fulani de la literatura yoruba; por nacionalidad, hablaríamos entonces de literatura marroquí frente a la literatura keniata; en función de su lengua, podría ser literatura xhosa o bien anglófona; a partir del género literario, tendríamos categorías como poesía y epopeya; si atendemos a las generaciones que las produjeron, separaríamos las precolonialistas de las poscolonialistas; respecto del sexo del autor, sería femenina o masculina; y así un muy largo etcétera. Esto prueba que

these many approaches suggest not only the diversity and complexity of life on the African continent and in its diasporas but also the stuff of which literature is made: language, aesthetic and literary traditions, culture and history, sociopolitical reality» (Julien 2014: 212).

Es más que patente, pues, la dificultad de su estudio, delimitación e incluso trazabilidad, lo cual hace más complicado aún abordar las propiedades y la idiosincrasia de estas peculiares formas de escritura. Para cerrar esta cuestión, se puede decir con Kane (1991: 17-18) que

l'établissement de l'histoire littéraire africaine dans des cadres plus restreints permettra de mieux appréhender ces problèmes et peut être de leur trouver des solutions, de mieux intégrer à l'histoire littéraire, à l'explication historique, l'influence des sciences annexes à la littérature, l'influence de l'art, de la politique, des mutations socio-économiques; bref, de ne plus faire de l'histoire littéraire une juxtaposition sans fin, sans explications suffisantes, des faits et de dates.

\section{ACERCAMIENTO A LA LITERATURA AFRICANA POSCOLONIAL EN LENGUAS EUROPEAS}

Emplear términos como literatura africana (y más específicamente, el de literatura africana femenina que abordaremos a continuación) implica adentrarse en un espacio en el que interviene todo tipo de factores: geográficos, sociopolíticos, culturales, lingüísticos... En este sentido, Díaz (2001: 115-116) precisa que el término literatura africana sirve para una especificación geográfica, pero que abarca producciones tan diversas que solo enumerarlas sería una tarea difícil:

Car à la classification en littératures nationales l'on devrait ajouter un critère de différentiation interne, c'est-à-dire distinguer les littératures provenant d'aires 
culturelles qui ne coïncident pas exactement avec les États modernes issus des indépendances. Sans oublier les littératures écrites en langues non européennes et les littératures orales.

Y un poco más adelante insiste en que en la literatura africana no se puede olvidar un hecho característico, constitutivo de la literatura: la intertextualidad. En sus palabras (2001: 117):

Ainsi, chercher (et même trouver) des spécificités exclusives - dans le double sens du mot- dans la littérature africaine contemporaine suppose la négation de l'intertextualité qui est à la base de la création littéraire et l'acceptation du principe de non-communication entre les différentes cultures et modes de vie. Principes qui, aujourd'hui, sont insoutenables et, à la limite, «non corrects».

Y, por supuesto, el concepto de literatura nacional está ligado indisolublemente al de lengua nacional, un problema central del que se ha ocupado Kesteloot (2009: 446-452):

La cuestión que se plantea al hablar de literatura nacional es evidentemente la de la lengua nacional, a la que por supuesto se le supone la función de vehicular toda la literatura endógena e indígena. ¿Podríamos reducir la literatura africana a los textos escritos en francés (o en inglés y portugués) y olvidar el importante corpus de textos transmitidos en las lenguas africanas? [...]. Ya hemos hablado de las investigaciones iniciadas a partir de 1960 sobre epopeyas, cuentos, cantos, fábulas, etcétera. Pero eran menos conocidos los testimonios de la literatura escrita en lengua africana. [...]. Los países francófonos padecieron, pues, lo que puede considerarse, sin temor a exagerar, un traumatismo cultural que explica diversas actitudes específicas actuales ${ }^{4}$.

Al hablar de «la literatura africana contemporánea», es imprescindible tener en cuenta que la década de los ochenta del siglo pasado se caracterizó, en África, por el incremento de la deuda externa y la dependencia del FMI. Consecuencia inmediata de ello fue el llamado Plan de Ajuste Estructural, que se puso en marcha a partir de 1982 y conllevó la devaluación de las monedas africanas y una mayor restricción de los presupuestos estatales (Díaz, 2007: 85-107). Mientras que las antiguas potencias colonizadoras se desentendían de las que fueron sus colonias, los africanos ni siquiera tenían en mente la posibilidad de emigrar al llamado Primer Mundo (a la Terre Promise, en palabras de la autora senegalesa Ken Bugul), pues en ese momento la economía europea no estaba preparada para la llegada masiva

${ }^{4}$ Y continúa Kesteloot (2009: 449): «El problema mucho más generalizado de los intelectuales y estudiantes cada vez más disglósicos [sic], que viven entre dos registros lingüísticos, uno que le da acceso a la zona de sensibilidad social y familiar, y otro a la de instrucción y la vida intelectual. Éstos se encuentran totalmente perdidos cuando tienen que expresar sus sentimientos en francés o sus ideas en baulé». 
de extranjeros en busca de trabajo. En tal situación comienzan a estallar conflictos armados por todo el continente, como fueron las guerras étnicas en Ruanda o la guerra civil de Sierra Leona. De todo ello nos informa cumplidamente el periodista polaco Ryszard Kapuściński en su libro Ébano5 , donde leemos lo siguiente:

Corría mediados de los años setenta. África acababa de entrar en la época de sus dos décadas más oscuras. Guerras civiles, revueltas, golpes de Estado, masacres y, junto con ello, el hambre que empezaron a padecer millones de personas que habitaban en el territorio del Sahel (Âfrica Occidental) y en África Oriental (sobre todo en Sudán, Chad, Etiopía y Somalia): éstos eran algunos de los síntomas de la crisis. Se había acabado la época llena de promesas y esperanzas de los años cincuenta y sesenta. En su transcurso, la mayoría de los países del continente se había liberado del colonialismo y había empezado una nueva andadura de Estados independientes. En las ciencias políticas y sociales de aquellos años predominaba en el mundo la idea generalizada de que la libertad automáticamente traería el bienestar, de que de un soplo, en un santiamén, la libertad convertiría la pobreza antigua en un mundo donde manarían la leche y la miel.

Asimismo, Frederick Cooper, en la introducción a su muy recomendable publicación titulada Africa since 1940 (2009/2002), se hace eco de lo acaecido durante esta época y, entre otras afirmaciones, leemos:

In the mid-twentieth century, the political meaning of Africa could be defined in different ways. To Pan-Africanist, the diaspora was the relevant unit. For Franz Fanon, politics were defined by imperialism, and he deprecated the idea of black nationality in favor of a conception of the unity of people oppressed by colonization [...]. In the 1959s they shared struggle against colonial powers, for the building up of national economies, and for national dignity, gave rise to a militant conception of the 'Third-World' -neither capitalist nor communist, uniting Asia, Latin America, and Africa against 'the North' or 'imperialist' powers» (2009/2002: 13);

y, más adelante continúa:

Some argue that the end of colonialism meant only that the occupants of government buildings changed, that colonialism gave way to neocolonialism. It is indeed essential to ask just how much autonomy the governments of new states -many of them small, all of them poor- actually had, and whether states from the North (the United States as well as the former colonial powers) and institutions such as international banks and multinational corporations continued to exercise economic and political power even when formal sovereignty was passed on. But one should not substitute a hasty answer for a good question (2009/2002: 15).

5 Pongo este ejemplo del capítulo doce, titulado «Lalibela 1975», pero hay más textos del mismo carácter en este libro, que constituye una fuente fiable para conocer la situación africana. 
En este contexto, muy pocos países comienzan a solucionar sus problemas: es el caso, por ejemplo, de Sudáfrica, donde finaliza el apartheid al llegar Mandela al poder. Y, como no podía ser de otra manera, esta complicada situación política, económica y social se ve reflejada en la literatura: comienza una escritura polifónica en la que el pueblo se debate entre lo puramente local y los macroproblemas que asolan al continente. La situación económica que marca la realidad del continente conllevará el drama privado de personajes que huyen de sí mismos. El exilio, la búsqueda de identidad y la introspección personal son temas recurrentes que acrecientan este drama interior.

\section{LA LITERATURA AFRICANA ESCRITA POR MUJERES}

Pues bien, en este complicado contexto identitario de colonización cultural, surge, en el África negra de lengua francesa, un período literario que se conoce comúnmente como el "comienzo del desencanto», que ocupa los años que van entre 1969 y 1985: aquí se sitúan los orígenes de la literatura africana escrita por mujeres ${ }^{6}$. Kesteloot (2009: 363) da comienzo al capítulo homónimo de su Historia de la literatura negroafricana como sigue:

Para definir el sentimiento que paulatinamente fue invadiendo el universo literario africano, Jacques Chevrier empleó la hermosa palabra «desencanto». En efecto, las bodas de los Orfeos negros con África, con la negritud, su Eurídice perdida y recuperada, no duraron demasiado. La euforia de las independencias se deshilachó demasiado deprisa.

Así, hasta la década de los ochenta, la novela africana se expande conservando grosso modo sus rasgos principales hasta ese momento: una escritura y una estructura lineal y realista, aunque con unas temáticas algo diferentes de las que aparecen en el siguiente período, como consecuencia de un cambio en los puntos de vista, relacionada en parte con la crítica dirigida a la negritud (Kesteloot, 2009: 374). A partir de entonces, la literatura africana experimenta una vitalidad asombrosa:

${ }^{6}$ Cf. Elena Cuasante (2007a): «De manera más o menos unánime, los especialistas sitúan los orígenes de la literatura africana escrita por mujeres en los años que siguieron a las Independencias, más concretamente en el período denominado de "desencanto" (1969-1985)». Aunque, inmediatamente, añade que tal afirmación requiere algunas precisiones: «En primer lugar, hay textos anteriores a esta fecha [1969] que, por razones de cánones literarios, no han contado con el interés de la crítica. En segundo lugar, y aunque es cierto que el primer texto literario femenino africano - nos referimos a Rencontres essentielles, de Thérèse Kouh-Moukoury- sale al mercado en 1969, la mayoría de las publicaciones se agrupan en los años que van de 1975 a 1983. Es precisamente en esta fecha, 1983, cuando Les Nouvelles Éditions Africaines editan Le baobab fou, de Marétou Mbaye, obra que será objeto del presente artículo». La profesora Cuasante ofrece siempre 1983 como el año de la primera edición de Le baobab fou: sin embargo, se equivoca en un año, ya que la primera edición de esta obra data de 1982. 
su producción es abundante y diversa y los escritores africanos utilizan todas las estrategias literarias a su alcance para expresar el malestar de las sociedades africanas actuales. Así afirma Díaz (2007: 87):

En esta apocalipsis polifónica, no podían faltar las voces de las mujeres y la denuncia de su particular situación. De hecho, se tendrá que esperar a la entrada de las mujeres en la literatura para encontrar una óptica distinta, un cambio de enfoque que nos permite comprender la otra cara, hasta ahora oculta de la realidad africana: el mundo privado, doméstico, las relaciones familiares.

Como señalaba al inicio, si bien las escritoras africanas no han recibido tanta atención por parte de los estudiosos, su producción literaria ha estado al mismo nivel que la de los hombres. La literatura femenina poscolonial africana florece con la llamada segunda generación de escritoras, fundamentalmente a partir de la década de los ochenta. Hasta esa fecha, la escritura y la crítica al colonialismo de los autores africanos no se había expresado a través de la voz de las mujeres. Como indica Boukari (2012: 4): «In the context of African countries, like in other patriarchal societies around the world, men were the first to write after colonialism ended».

La escritura masculina ${ }^{7}$ presentaba las temáticas clásicas de esa época como propias, como experiencias y opiniones que solo incumbían a los hombres, relegando así la escritura femenina a esferas secundarias. En palabras de Julien (2014: 220):

What was missing in the early chorus of voices denouncing the arrogance and violence of the various form of colonialism, and what was in some cases ignored, were female voices. As recent writing by women makes clear, gender gives writing a particular cast. Anticolonial male writers critique the imperial and colonial Project for its racism and oppression, but they nonetheless [...] portray these matters as they pertain to men, and they formulate a vision of Independence or of utopias in which women are either "goddesses», such as muses and idealized mothers or mere helpmates.

Sin embargo, como también indica Sidikou (2009: 259):

Thus, precolonial, colonial, and present experiences shaped the writings of most of the women writers who were products of French colonialism. It is against this background that Ken Bugul exposes her social, historial, and political positions in her connections to Senegalese society, Africa, Europe and the world.

De la misma opinión es Bernard Mouralis, quien se refiere a ello en un capítulo de su obra titulado "La parole des femmes. D’Aoua Keita à Marie Ndiaye»,

7 Según Pierrette Herzberger-Fofana (2000: 8), «les premiers écrits sur la femme africaine datent du XIXème siècle et proviennent d'anthropologues, missionnaires et gouverneurs qui tous, n'avaient qu'un but, justifier l'esclavage ou la mission civilisatrice et renforcer ainsi les coutumes dans leur aspects coercitif». 
(2007: 319-320). Allí matiza que, efectivamente, hasta los años setenta, la literatura africana había sido escrita fundamentalmente por hombres. En la mayor parte de los casos, la visión de lo femenino se daba a través de la focalización de la figura materna, aunque es cierto que muchos escritores insistieron también en la situación social de las mujeres en la sociedad africana, tanto en la época colonial como después de la independencia de los distintos países.

En esa literatura masculina aparecen dos tipos de imagen femenina: una imagen realista, que nos hace partícipes de la situación de desigualdad, discriminación y prejuicios que sufre la mujer africana; y otra utópica, que nos da una visión de la mujer desde una perspectiva que no coincide con su situación real en esos países. Es importante tener en cuenta esta dualidad, ya que, de alguna manera, la literatura escrita por mujeres puede entenderse también como una reacción a las obras masculinas que durante mucho tiempo marcaron la producción negroafricana. Y, en esta misma línea, Man (2007: 2-3) empieza su tesina casi con estas mismas palabras, que por su interés no me resisto a reproducir:

Pendant longtemps la littérature africaine a été présentée comme le domaine réservé des hommes. De la période coloniale aux années 1970, les hommes dominent le milieu littéraire. Toutefois quelques écrivaines réussissent à y forcer leur présence. [...]. Le petit nombre de ces écrivaines atteste de la présence effective des femmes dans le milieu littéraire africain. Les femmes n'étaient pas invisibles seulement dans les romans, elles l'étaient aussi dans les critiques littéraires. [...]. Il n'est pas juste cependant d'affirmer que les écrivains n'ont jamais représenté les femmes dans leurs romans. Toutefois les héroïnes des romans des écrivains africains ne représentaient que des images muettes. Très souvent ces héroïnes symbolisaient la mère vertueuse et combattante qui n'était autre que l'Afrique en lutte.

La literatura escrita por mujeres en África presenta muchas coincidencias con la de cualquier otra sociedad; sin embargo, pone de manifiesto una práctica y una temática diferentes. La reciente historia de este continente da forma a la producción literaria femenina, en la que la literatura oral, en la que la mujer desempeña un papel activo, coexiste con la escrita en lenguas europeas (sobre todo, inglés, francés y neerlandés $)^{8}$, lo cual coloca a la mujer en una situación particular. Según Díaz Narbona (2007: 88-89):

Se acepta que la literatura tradicional es el máximo exponente de la literatura de los pueblos [...]. Este hecho es doblemente importante en aquellas civilizaciones que, como la africana, son eminentemente orales. En estas literaturas, además de los detentores «oficiales» de la palabra, las mujeres actúan como primeras trans-

8 Según Mouralis (2007: 335-436), las literaturas francófonas de África y las Antillas presentan una particularidad evidente de entrada y, a menudo, señalada: conceden gran importancia a la oralidad, a la que se refieren explícitamente como si fuera un dato fundamental con el que los escritores deben contar. En esto se diferencian de las literaturas europeas, que son literaturas de lo escrito. También distingue Mouralis (2007: 338) entre lo oral, lo escrito y lo impreso. 
misoras. [...]. Tras la instauración de la colonización y el posterior ascenso de la literatura africana escrita en lenguas europeas, la que puede ser considerada la primera narradora, la mujer, guarda silencio por las razones que podrían considerarse «tradicionales» - en el sentido de habituales- en todas las culturas.

Pero, si la literatura tradicional africana traslada con nitidez la imagen de la mujer, que es la figura encargada de transmitir la sabiduría de generación en generación, en la realidad cotidiana el espacio doméstico no sufre la transformación que la política colonial pretendía, y la tradicional exclusión de las mujeres del mundo de la instrucción convierte la escritura en un medio más de segregación.

Por otra parte, el inicio de la literatura africana escrita en lenguas europeas se ve marcado por la literatura de corte exótico y colonial que se hacía en Europa. La mirada del blanco es asimilada por los primeros escritores africanos, que transmiten los clichés y el punto de vista europeo en sus novelas. Con respecto a la literatura hecha por mujeres, a pesar de que antes de las independencias de los países africanos ya algunas mujeres escribían poemas, cuentos infantiles y relatos cortos, estos primeros textos no fueron tenidos en cuenta por la crítica, que los consideró carentes de valor literario. Sin embargo, de nuevo según Díaz (2007: 91), «lo que parece una realidad es que los primeros textos femeninos pretenden subvertir la imagen femenina trasladada por los escritores africanos».

Así, si bien el nacimiento de la verdadera literatura africana escrita por mujeres $^{10}$ se sitúa en los años ochenta, el primer texto importante conocido es Ngonda ${ }^{11}$, publicado en 1958 y atribuido a la camerunesa Marie-Clarie Matip. Este texto no tuvo mayor repercusión en la crítica literaria; de hecho es más conocida la obra de la también camerunesa Thérèse Kuoh-Moukoury, autora de Rencontres essentielles, publicada en 1969. Junto a estas, representan a esta primera generación autoras como Lilith Kakaza o Victoria Swaartboo, ambas escritoras en xhosa, así como Violet Dube, escritora en zulú, o Adelaide Casely-Hayford, nacida en Sierra Leona y educada en Europa. Estas mujeres, educadas en escuelas coloniales, comenzaron a escribir al tiempo que sus países obtenían sus respectivas independencias.

${ }^{9}$ La ponemos en cursiva para llamar la atención sobre el hecho de que es una denominación al uso que, como se verá explicado más adelante, no compartimos por considerarla un tanto sesgada, eurocéntrica y reduccionista.

${ }_{10}$ Aunque Jacques Chevrier ponía en duda la existencia de una literatura escrita por mujeres cuando aseguraba "Si l'on rend un juste hommage à la littérature écrite par des femmes-écrivains, peut-être est-il encore trop tôt pour parler d'une écriture féminine» (1984: 153).

${ }^{11}$ Gonda significa 'muchacha' y es una novela fundacional a la que se refieren todos los estudiosos que hemos tenido en cuenta: así, por ejemplo, Elena Cuasante (2006: 217-220; 2007a: 2; 2007b: 55 «Ngonda-que significa "jovencita"-») la nombra en todos sus trabajos. Y los otros autores, lo mismo. Hemos mantenido esta amplia referencia por su gran interés «informativo». $C f$. también Díaz Narbona (2007: 91-93). 
Igualmente tenemos los casos de la marfileña Mavel Dove Danquah ${ }^{12}$, la keniata Grace Ogot, la sudafricana Noni Javabu ${ }^{13}$, la nigeriana Flora Nwapa o la escritora ganesa Ama Ata Aidoo.

Así nacen los primeros textos literarios escritos por mujeres africanas. Todos ellos, hasta los primeros ochenta, coinciden en la temática narrativa: relatan sus vidas interiores, la de los espacios privados en que «son» ellas, al tiempo que van dejando entrever las primeras críticas hacia el mundo en que vivían; las escritoras de esta llamada primera generación retratan y denuncian a través de sus yoes el mundo africano, el mundo de los hombres, el mundo de las mujeres, un mundo en el que el papel que se les había asignado les quedaba estrecho (Díaz Narbona 2007: 92).

Más tarde, en la década de los ochenta, surge la llamada segunda generación de escritoras. Los especialistas señalan como representantes de este grupo a la senegalesa Mariama Bâ (Une si longue Lettre, 1979 y Un chant écarlate, 1981), a la también senegalesa Aminata Sow Fall (La Grève des Battu, 1979), a la nigeriana Buchi Emecheta (Joys of Motherhood, 1979), a la primera escritora gabonesa, Angèle Ntyugwetondo Rawiri (Elonga, 1980), a la senegalesa Ken Bugul (Le baobab fou, 1982), a la marfileña Véronique Tadjo ${ }^{14}$ (Laterité, 1984) y a la camerunesa Calixthe Beyala (C'est le soleil qui m’a brûlée, 1987). Esta nueva generación de escritoras guarda relación sin duda con sus predecesoras, pero anuncian ya un cambio en la voz del «yo» femenino, que plantea abiertamente una denuncia de la situación de las mujeres en el continente africano. Man (2007: 11) nos dice al respecto:

Pour résumer, nous dirons qu'au commencement l'œuvre féminine est née dans la douleur. Elle est issue du refus du rejet, du silence et du reniement et du besoin d'exprimer ses douleurs. C'est pour cela que l'écriture féminine africaine est caractérisée par son côté personnel et intime. Les premiers romans des écrivaines africaines sont pour la plupart des œuvres autobiographiques. Pourtant une fois que les femmes se sont mises à exposer leurs maux, les injustices, les inégalités, bref leur mécontentement, elles ont découvert que toute la société a besoin d'être changée et guérie. Leur prise de conscience ne pouvait pas se faire sans la prise en compte des maux de la société. Elles sont en effet partie intégrante de cette société. Par exemple, pour Mariama Bâ, les hommes semblent tous pareils. De sorte que sa réflexion ne s'est plus limitée à l'homme-mâle mais s'est étendue à l'homme-humanité. Elle a compris que les conflits sont inutiles.

${ }^{12}$ Según la tesis de Kofigah (1996): «Before the emergence of such strong exponents of literary feminism as Efua Sutherland and Ama Ata Aidoo, there was Mabel Dove Danquah, the trail-blazing feminist».

${ }^{13}$ Según la Encyclopedia of women's autography: $K-Z$ (2005:20): «Noni Jabavu’s two autobiographies Drawn in Colour: African Contrasts (1960) and The Ochre People (1963) were the first published by a black South African woman $\&$ are examples of autoethnographies».

${ }_{14}$ Autora de L'ombre d'Imana (2000), traducida al español bajo el título La sombra de Imana, Ediciones El Cobre, 2003), por Nuria Viver Barri. Otras obras de Véronique Tadjo también han sido traducidas al catalán (La dansa de la pantera, Editorial Cruilla, S.A., 1999) y al español ( $L a$ canción de la vida y otros cuentos, Editorial Siruela, 2006). 
Y en términos parecidos se expresa Cuasante (2006: 216-217):

Depuis leur entrée dans l'univers littéraire africain -qui se produit, comme nous le savons, aux environs des années $70-$, les femmes se sont montrées si actives que l'on peut bien aujourd'hui distinguer, avec la plupart de critiques, deux générations à l'intérieur de l'écriture féminine. Une telle distinction obéit notamment à une série de transformations de base, touchant respectivement la dimension formelle, fonctionnelle et thématique du récit féminin. En effet, à partir de 1985, la présence presque exclusive de textes factuels diminue face à la prolifération des textes de fiction; la littérature, jusque là principalement descriptive, acquiert peu à peu des résonances plus revendicatives; finalement, dans l'espace du raconté, on observe une très nette diversification thématique.

De esta manera, la literatura africana femenina cambia de orientación ${ }^{15}$ a partir de los años ochenta, pero conserva sus temáticas principales: la reapropiación del cuerpo como primera fase de una construcción personal y el enjuiciamiento de los hombres. Además del carácter autobiográfico, esta segunda generación de escritoras africanas comparte, según Man (2007: 27-28 y 29, respectivamente), unos rasgos estilísticos determinados, entre los que cita:

Le sixième critère se situe au niveau des figures de style. Les œuvres postcoloniales utilisent les figures de style comme la métaphore, la parodie, la répétition. Elles se servent aussi de l'intertextualité pour instaurer une sorte de dialogue entre les textes. Par exemple on trouvera dans plusieurs romans le même thème du départ. L'intertextualité est un thème dominant dans les romans postcoloniaux parce qu'il affirme et confirme la pluralité identitaire des textes. [...]. Les œuvres postcoloniales se reconnaissent aussi par la pluralité des voix.

Ahora esta escritura es ya un arma de protesta, es un elemento de subversión, cuya meta es transformar la sociedad, si bien sus objetivos van más allá de los del feminismo occidental ${ }^{16}$. Sin embargo, y a pesar de ello, coincido con Díaz Narbona en que las escritoras no parecen sentirse encorsetadas en una expresión permanente de denuncia; ya, a finales de los noventa, se ha afianzado y ha alcanzado madurez.

Así, desde aquella época la literatura escrita por mujeres no ha parado de crecer de manera exponencial. Hoy en día muchos de esos rasgos siguen presentes en las obras pero muchos otros se añaden: la situación social de estas en el continente ha ido evolucionando y con ello su escritura. Por otra parte, la escritura diaspórica femenina ha tomado un papel muy relevante en la escena literaria mundial, con

15 Asimismo, Eileen Julien afirmaba (2014:220): «Women writers of that era and new writers, however, introduce matters of gender explicitely, as they nonetheless critique the underpinnings of the colonial project or its aftermath".

16 Cf. Díaz Narbona (2007: 97-98): «Las mujeres se convierten en "misóviras” (término que crea y populariza la camerunesa Werewere Liking, en su obra Elle sera de jaspe et de corail, 1983), o sea, mujeres que no consiguen encontrar un hombre digno de admiración». 
representantes como la senegalesa Fatou Diome o la conocidísima Chimamanda Ngozie Adichie. En palabras de Edoro (2016):

Past generations of African writers wanted literature to address the burden of colonialism and various social ills. [...]. The current generation of African readers are driven more by their tastes and passions than by allegiance to some abstract political idea. They are young, open, and unconventional in their interests. They are social media savvy and dependent on mobile technology for media consumption. [...]. The obsession with realist fiction that defined older generations has given way to an avid interest in speculative writing -fantasy, science fiction- but also in experimental narratives, pulp-fiction, and other offbeat genres. [...] 50 years ago, we said that the reader of African fiction wanted to be saved from colonial mentality. Today, African readers simply want stories that entertain and inspire them.

En la actualidad las escrituras femeninas se han tornado hacia géneros muy diversos, como el cómic en el caso de la marfileña Marguerite Abouet con Aya de Yopougon (Gallimard, 2005), la ciencia ficción o la literatura de viajes de la mano de las nigerianas Nnedi Okorafor con Lagoon (Hodder \& Stoughton, 2014) y Noo Saro-Wiwa con Travels in Nigeria (Granta Books, 2012), respectivamente. La literatura romántica o erótica también tiene a sus representantes, como son la consagrada escritora camerunesa Leonora Miano con sus dos antologías editadas por Mémoire d'encrier: Première nuit, une anthologie du désir (2014) y Volcaniques, une anthologie du plaisir (2015); o la sudafricana Amina Thula con $A$ taste of love (Ankara Press, 2014) y la nigeriana Sifa Asani Gowon con The elevator Kiss (Ankara Press, 2015). Escriben también thrillers, y muchas de ellas están muy activas en plataformas como Twitter, en donde sus microrrelatos o twitteratura tienen miles de seguidores, como los de la botsuanesa Siyanda Mohutsiwa o en sus exitosos blogs, como es el caso de la marfileña Edwige Renée Dro. Las plataformas como TEDs son, asimismo, otro de los medios de expresión de estas autoras. Véase el caso de Adichie, con sus intervenciones tituladas The danger of a single story, o la archiconocida We should all be feminist, esta última publicada en inglés y recientemente traducida a numerosas lenguas, entre otras el español.

A modo de conclusión, vemos pues cómo la literatura escrita por las mujeres africanas ha sido una realidad desde la época colonial, hecho que más tarde evolucionó en el marco del contexto histórico y sociopolítico de la época poscolonial y la situación de la mujer africana en aquel entonces. En la actualidad, la literatura africana femenina encuentra, desde hace ya unas décadas, nuevas formas contemporáneas de expresión, comunes a las de otras creadoras reconocidas por el canon de la literatura universal, en el que ocupan un papel cada vez más predominante y de impacto en el panorama literario internacional. La heterogeneidad de sus creaciones, las diversas representaciones locales y diaspóricas de sus yoes del siglo XXI, el lenguaje moderno y desenvuelto de sus producciones, los estilos y formatos diversos que nos presentan y las temáticas y las miríadas de nuevas visiones y representaciones de Africa que nos ofrecen son testigos de la nueva era de la literatura en manos de estas mujeres. 


\section{BIBLIOGRAFÍA}

Achebe, C. (1965/1997). «English and the African Writer». Transition 75/76, The Anniversary Issue: Selections from Transition 1961-1976, pp. 342-349.

Adichie, C.N. (2014). We should all be feminists. New York: Penguin Random House, Vintage Books.

Boukari, S. (2012). African Literature: Gender Discourse, Religious Values, and the African Worldview. Nigeria: African Heritage Press.

Chevrier, J. (1978). «L'écrivain français devant la langue française». L’Afrique littéraire et artistique, 49, pp. 47-52.

Chevrier, J. (1984). Anthologie africaine d'expression française (vol. 1 et vol. 2). Paris: Hatier.

Cooper, F. (2002). Africa since 1940: the past of the present (vol. 1). Cambridge University Press.

Cuasante Fernández, E. (2006). «Mères absentes-mères coupables las rapports familiaux dans les premiers textes féminins de l'Afrique noire». Francofonía $15 .<$ http://rodin.uca.es:8081/ xmlui/bitstream/handle/10498/8421/32639752.pdf?sequence $=1>$.

Cuasante Fernández, E. (2007a). "Le baobab fou de Ken Bugul: una escritura de desarraigo». Afroeuropa. Journal of Afroeuropean Studies 1, 2. <http://journal.afroeuropa.eu/index.php/ afroeuropa/article/viewDownloadInterstitial/19/18>.

Cuasante Fernández, E. (2007b). «La literatura autobiográfica negro-africana: la naturalización de un legado colonial». Babilónia. Revista lusófona de línguas, culturas e tradução 5, 43-56. $<$ http://revistas.ulusofona.pt/index.php/babilonia/article/viewFile/875/709>.

Díaz Narbona, I. (2001). «Une lecture à rebrousse-temps de l'oeuvre de Ken Bugul: critique féministe, critique africaniste». Études françaises 37(2), 115-13. <http://id.erudit.org/ iderudit/009011ar>.

Díaz Narbona, I. (2007). Literaturas del África subsahariana y del Océano Índico. Cádiz: Universidad de Cádiz.

Herzberger-Fofana, P. (2000). Littérature féminine francophone d'Afrique noire. Paris: L'Harmattan.

Julien, E. (2014). "Literature in Africa», en M. Grosz-Ngate, J.H. Hanson y P. O’Meara. (eds.) (2014 $\left.{ }^{4}\right)$, Africa. Bloomington: Indiana University Press, 209-232.

KANE, M. (1991). «Sur l'histoire littéraire de l'Afrique subsaharienne francophone». Études littéraires 24, pp. 9-28.

KapuścińsKi, R. (2000). Ébano. Barcelona: Anagrama.

Kesteloot, L. (2001). Histoire de la littérature négro-africaine. Paris: Karthala.

Kesteloot, L. (2009). Historia de la literatura negroafricana: una visión panorámica desde la francofonía. Barcelona: El Cobre.

Kofigah, F.E. (1996). The Writing of Mabel Dove Danquah. Kumasi: Kwame Nkrumah University of Science and Technology. Doctoral dissertation. <http://archive.is/qWBzS>.

Man, M. (2007). La folie, le mal de l'Afrique postcoloniale dans Le baobab fou et La folie et la mort de Ken Bugul. Columbia: University of Missouri. Tesis doctoral. <https://mospace.umsystem. edu/xmlui/bitstream/handle/10355/4794/research.pdf?sequence $=3>$.

Mouralis, B. (1997). «Autobiographies et récits de vie dans la littérature africaine. De Bakary Diallo à Mudimbe». Cahiers de littérature orale, 42, pp. 105-134. 
Mouralis, B. (2007). L'illusion de l'altérité: études de littérature africaine. París: Honoré Champion.

NGom, F. (2010). «Ajami scripts in the Senegalese Speech Community». Journal of Arabic and Islamic Studies 10(1), pp. 1-23.

Sidikou, A. (2009). «Every Choice is a Renunciation. Cultural Marks in ken Bugul's Riwan ou le chemin de sable», en C. Okonjo Ogunyemi y T. Jita Allan (eds.), The Twelve Best Books by African Women: Critical Readings. Ohio University Press, pp. 245-265. 
